\title{
Who's Contributing Most to American Neuroscience Journals: American or Foreign Authors?
}

\author{
(D) P. Charkhchi, (D) M. Mirbolouk, (1DR. Jalilian, and DD.M. Yousem
}

\begin{abstract}
BACKGROUND AND PURPOSE: With globalization, the contributions of authors from abroad to the American published literature has increased. We sought to determine the changes with time in the proportional contributions of American and non-American authors in the American neurosciences literature. We hypothesized the following: 1) During the past 21 years, manuscript contributions of American institutions have proportionally decreased in neuroradiology, more than in neurosurgery or neurology; 2) contributions of Asian institutions have affected neuroradiology more than neurosurgery and neurology; and 3) American articles garner more citations.
\end{abstract}

MATERIALS AND METHODS: We reviewed the May issues of 2 of the highest impact American-based neurology, neurosurgery, and neuroradiology journals published from 1997 to 2017 . We counted the number of articles published by nation based on the institution of origin. We looked at trends across time and compared neurology, neurosurgery, and neuroradiology journals. We also gathered data on the number of citations of each article by nationality.

RESULTS: We reviewed 3025 articles. There was a significantly lower ratio of American to non-American authorship in neuroradiology versus neurology/neurosurgery journals (odds ratio $=0.70 ; 95 \%$ confidence interval, $0.60-0.82$ ). There was a significantly decreasing trend in American authorship across the 21 years in neuroradiology. Of the countries outside the United States, Japan contributed most for neuroradiology and neurosurgery journals, and the UK, for neurology. American-authored articles were cited, on average, 1.25 times more frequently than non-American-authored articles.

CONCLUSIONS: Non-American contributions have impacted neuroradiology more than other clinical neuroscience fields with Asian authorship showing the greatest impact. That impact is growing, and the causes are manifold. Nonetheless American-authored articles are cited more.

$\mathbf{T}$

he number of neuroscience articles and journals has grown during the past decade. ${ }^{1}$

The authorship trend in neuroscience is changing. ${ }^{1}$ Although the United States along with European countries like Germany and the UK had been the dominant contributors to the neuroscience literature as a whole, countries in the Far East are contributing more and more to the academic world on the basis of trend lines from 2006 to 2015 . $^{1}$ This ever-changing landscape of authorship emphasizes the importance of examining this trend and any biases it may yield. Although Peccora et $\mathrm{al}^{2}$ reported that the number of publications in anesthesiology by American authors has

Received January 7, 2018; accepted after revision February 10

From the Department of Radiology and Radiological Science, Division of Neuroradiology, Johns Hopkins Medical Institutions, Baltimore, Maryland.

Please address correspondence to David M. Yousem, MD, MBA, Department of Radiology and Radiological Science, Division of Neuroradiology, Johns Hopkins Medical Institutions, 600 N Wolfe St, Baltimore, MD 21287; e-mail: dyousem1@jhu.edu

= Indicates article with supplemental on-line tables.

http://dx.doi.org/10.3174/ajnr.A5624 declined during the past decades, the authorship characteristics of clinical publications in neurology, neurosurgery, and neuroradiology have not been investigated.

This study aimed to assess changes in the contribution rates and impact of different nations (based on the first author's institution) on publications in the top American-published neurology, neurosurgery, and neuroradiology journals during a 21-year period.

We hypothesized the following: 1) Between 1997 and 2017, contributions from institutions outside the United States have increased significantly across the specialties, but most in neuroradiology; 2) the contributions from Asian institutions have affected neuroradiology more than neurosurgery and neurology; and 3) despite a growing number of international contributions to clinical neurosciences journals, American articles garner more citations per article published, possibly reflecting an implicit bias.

\section{MATERIALS AND METHODS}

We targeted 3 different clinical neurosciences fields: neurology, neurosurgery, and neuroradiology. We chose the 2 most cited journals published in the United States in these 3 fields: the Annals 


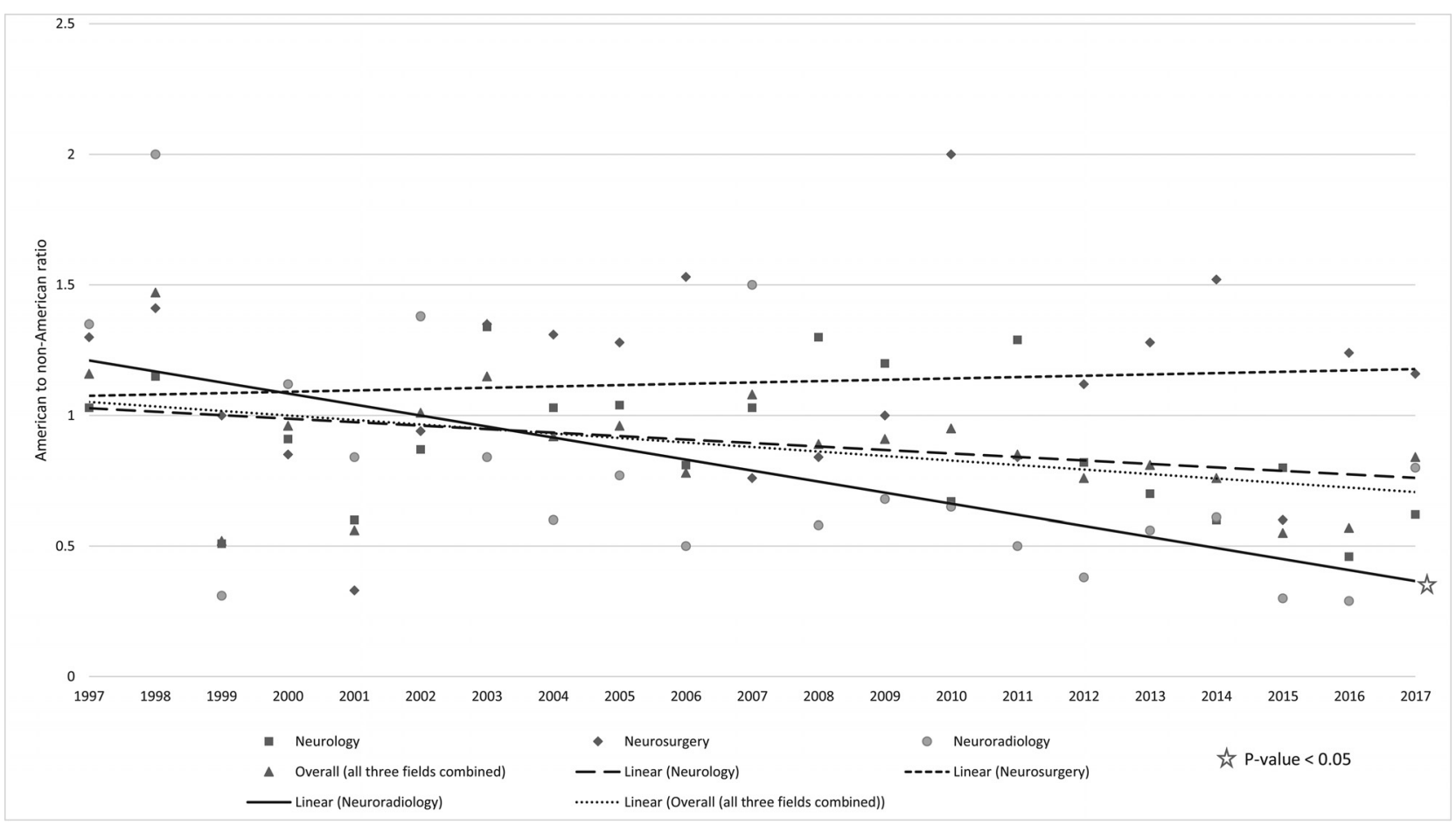

FIG 1. The ratio of American to non-American authorship falls significantly $(P<.05)$ during the 21 years for neuroradiology only.

of Neurology and Neurology in the field of neurology, ${ }^{3}$ the Journal of Neurosurgery and Journal of Neurotrauma in the field of neurosurgery, ${ }^{4}$ and the American Journal of Neuroradiology and Human Brain Mapping in neuroradiology. ${ }^{5}$

We collected information about the institution of origin of the first author of all articles in the May issue (a randomly selected month) of these 6 journals between the 1997 and 2017 as a proxy to track the trends during the past 21 years.

The country of the first author's institution was extracted for each article in the May issue of the 6 journals. We then used Google Scholar to track the number of citations of each article. We collected the cumulative number of citations of all articles from May 1997 to May 2017 by querying Google Scholar between September 18, 2017, and November 27, 2017. The articles and Google Scholar were accessed remotely using the electronic portal of our medical library through the Internet. ${ }^{6}$

Our study is a retrospective bibliometric analysis. All statistical analyses were performed using STATA, Version 11 (StataCorp, College Station, Texas). First, we used descriptive statistics to calculate the ratio of American to non-American institutions and the most frequent non-American countries publishing in American journals from 1997 to 2017. Continuous data were summarized using means and SDs; categoric data were summarized using weighted percentages. Then we performed logistic regression analysis to examine the difference in authors' nationalities (American to non-American ratio) and Asian contributions across the 3 neuroscience fields. To assess whether the ratio difference changed during the 21 years, we included the interaction term between the year of publication and each field into the logistic models. To assess the difference in the number of citations between articles originating in the United States and outside the United States among the 3 fields, we counted the citation numbers per article and then compared the average number of citations between American and non-American institutions in each year, from 1997 to 2017. In addition, we used Poisson regression analysis to assess the influence of nationality on the number of citations overall and in each field. Because articles published earlier may have garnered more citations, we also analyzed the citations in two 10-year periods (1997-2006 and 2007-2017).

When we assessed Asian countries for their contributions, we included Japan, South Korea, China, Taiwan, Singapore, and Thailand. We also looked at trends based on the continent of origin. ${ }^{7}$

\section{RESULTS}

Data were collected from 3025 articles: 1120 in neurology, 860 in neurosurgery, and 1045 in neuroradiology. In total, 1393 (46.0\%) articles were from American institutions and 1632 (54.0\%) were from non-American institutions.

Across the years studied, neuroradiology journals (compared with neurology and neurosurgery journals) showed the lowest American authorship rate in 2016, 2015, 2013, 2012, 2011, 2010, $2009,2008,2006,2005,2004,2003$, and 1999, representing 13/21 years studied (Fig 1). Neurology had the lowest American authorship rate in $5 / 21$ years $(2017,2014,2002,1998$, and 1997), with $3 / 21$ years $(2000,2001,2007)$ represented by neurosurgery (Online Table 1). There was a significantly lower ratio of American authorship to non-American in neuroradiology journals ( $\mathrm{OR}=$ 0.70; 95\% CI, 0.60-0.82). Compared with neuroradiology journals, neurology and neurosurgery journals had a higher ratio of American to non-American authorship ( $\mathrm{OR}=1.29 ; 95 \% \mathrm{CI}$, $1.09-1.53$ and $\mathrm{OR}=1.59 ; 95 \% \mathrm{CI}, 1.33-1.91$, respectively). There was a decreasing trend in the American authorship ratio across the 21 years in neuroradiology because there was a significant nega- 


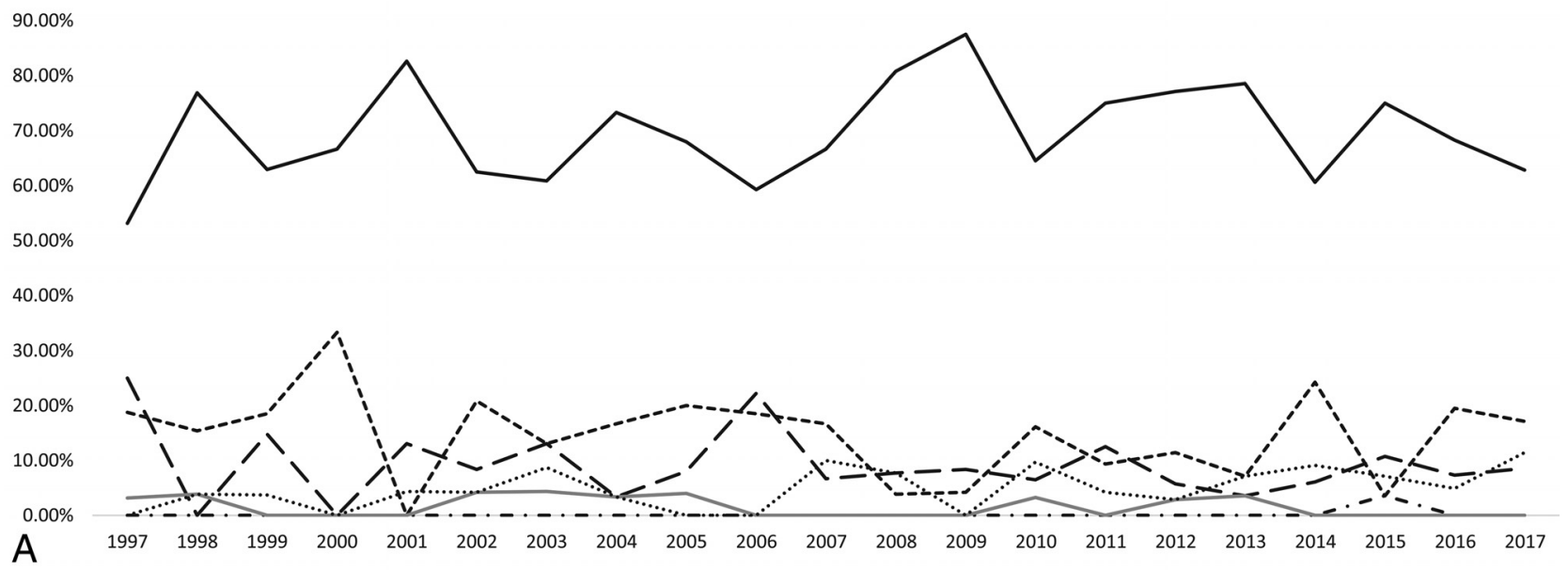

$100.00 \%$

$90.00 \%$

$80.00 \%$

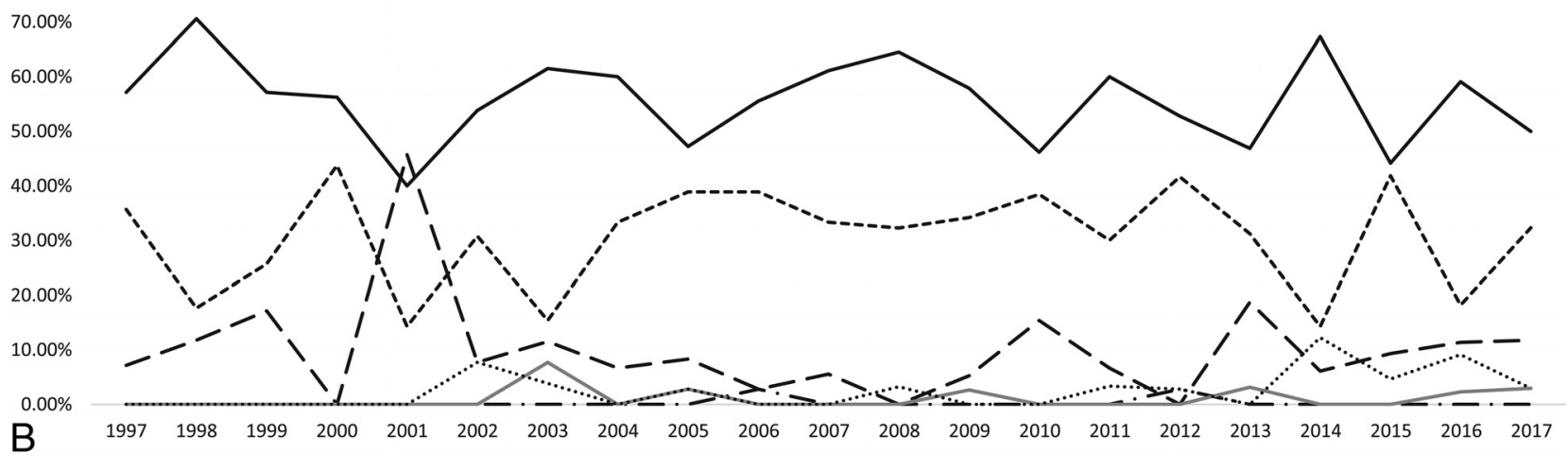

$100.00 \%$

$90.00 \%$

$80.00 \%$

$70.00 \%$

$60.00 \%$

$50.00 \%$

$40.00 \%$

$30.00 \%$

$20.00 \%$

$10.00 \%$

$0.00 \%$

C

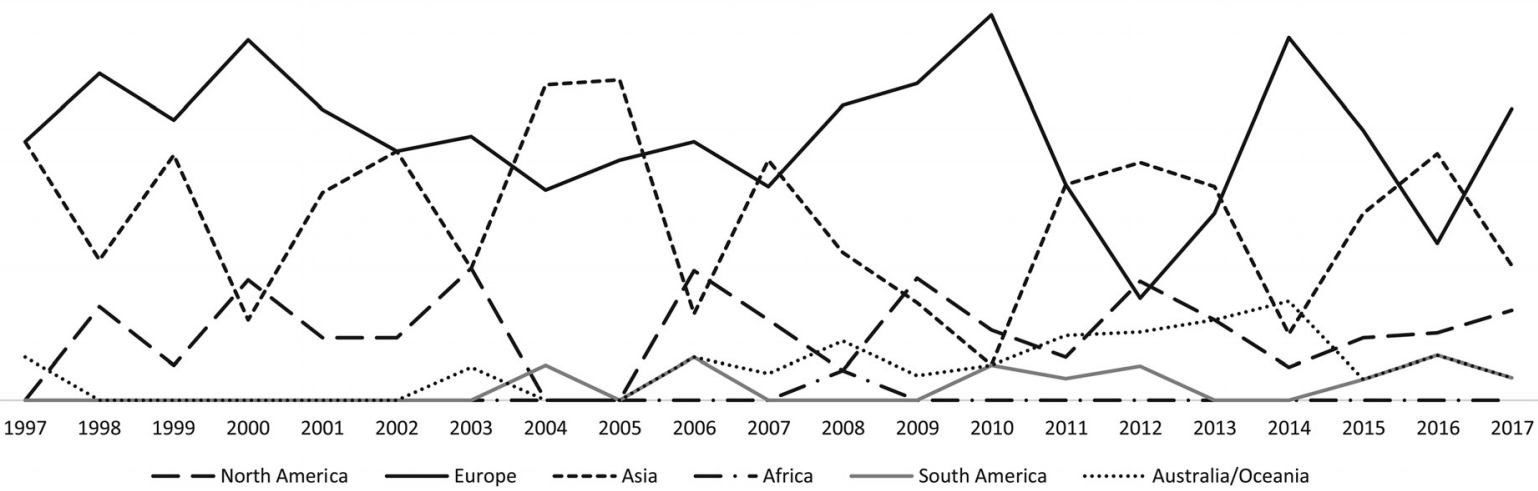

FIG 2. Participation of different continents $(\%)$ in American neurology $(A)$, neuroradiology $(B)$, and neurosurgery $(C)$ journals, excluding the United States. The trend of publications by continent is demonstrated over time by field showing the dominance of European contributors for neurology only.

tive interaction between the year of publication and the neuroradiology field (interaction term $=0.95 ; 95 \%$ CI, 0.93-0.97).

After excluding the United States, we observed that countries from Europe showed a higher percentage of participation in the 2 neurology journals reviewed for all 21 years followed by countries from Asia and North America (mainly Canada) for most years (Fig 2). We observed the same trend in neuroradiology for most years-that is, that Europe, as a continent, had more articles. In 


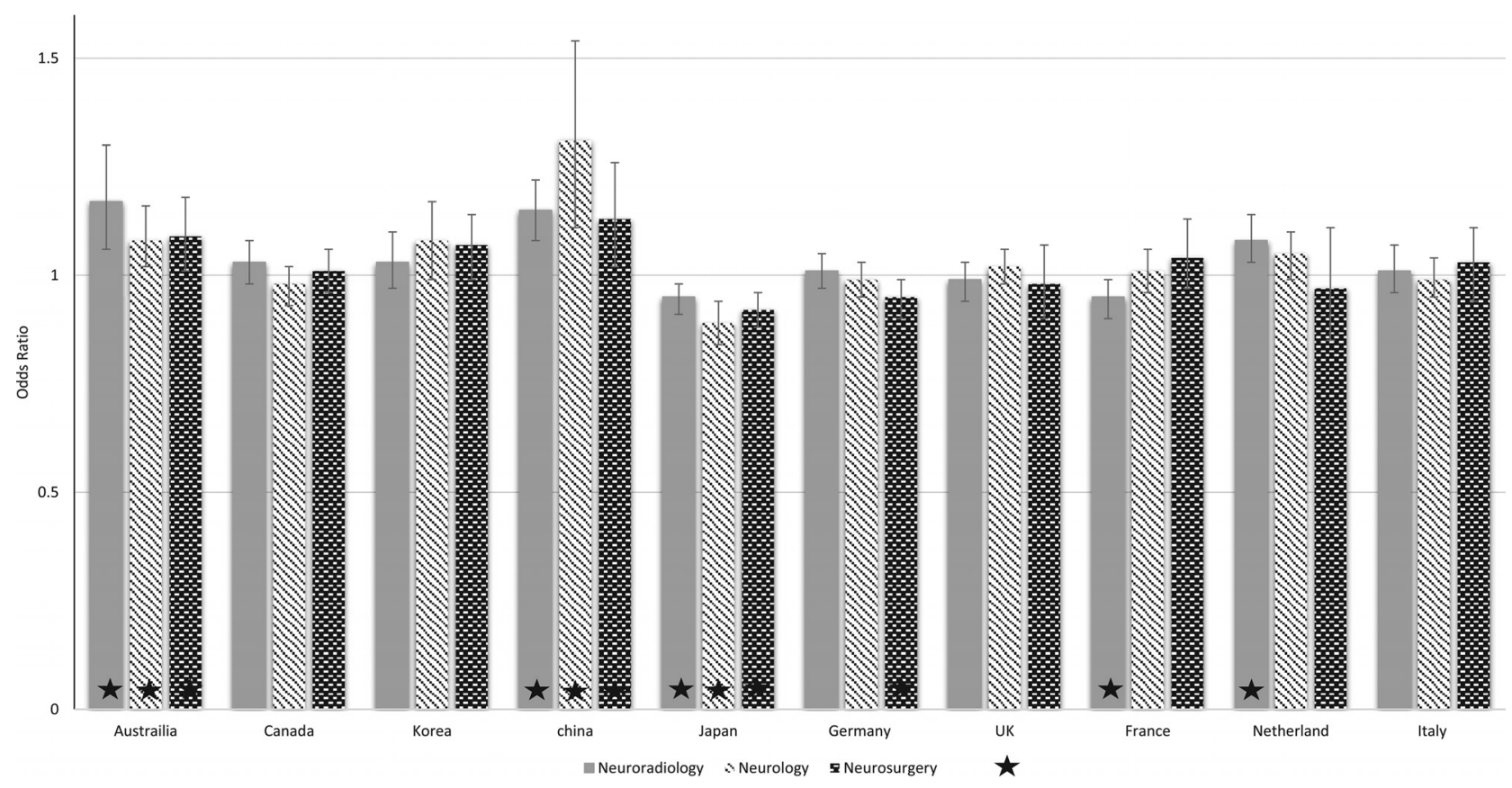

FIG 3. The contributions of China and Australia across all fields have significantly increased, while Japanese articles have shown a decline. $\star$ indicates a statistically significant difference at $P<.05$.

neurosurgery, the gap between the continents of Europe and Asia was less; we even observed higher participation of countries from Asia than Europe in 2004, 2005, 2007, 2012, 2013, and 2016 (Fig 3). Among countries with the highest rate of participation in the past 21 years in all 3 fields, Australia showed a significant, increasing trend of contributions in all 3 fields (neurology: $\mathrm{OR}=1.08$; 95\% CI, 1.01-1.15; neuroradiology: OR $=1.17$, 95\% CI, $1.06-$ 1.29; neurosurgery: $\mathrm{OR}=1.09 ; 95 \% \mathrm{CI}, 1.01-1.18)$. There was an increasing trend only in neuroradiology for the Netherlands $(\mathrm{OR}=1.08 ; 95 \% \mathrm{CI}, 1.02-1.40)$. There was a decreasing trend for France in neuroradiology ( $\mathrm{OR}=0.94 ; 95 \% \mathrm{CI}, 0.90-0.99)$, and a decreasing trend for Germany in neurosurgery $(\mathrm{OR}=0.94 ; 95 \%$ CI, 0.91-0.99) (Fig 3). Of the non-American neuroscience articles, Japanese institutions contributed 197/1632 (12.1\%) articles, the highest of any non-American country. The country that contributed most per year in neurology was the UK in 9/21 years (2016, 2015, 2013, 2012, 2010, 2009, 2003, 2002, 1999); in neurosurgery, it was Japan in 12/21 years $(2015,2013,2011,2007,2005$, 2004, 2003, 2002, 2001, 1999, 1998, 1997); and in neuroradiology, it was also Japan in 11/21 years (2010, 2009, 2007, 2006, 2005, 2004, 2002, 2001, 2000, 1999, 1997). Of 1632 neuroscience articles from non-American institutions, 376 (23.04\%) originated in Asian countries. Of the Far East Asian countries, Japan (52.39\%) had the highest article number followed by South Korea (20.74\%), China (19.41\%), Taiwan (5.59\%), Singapore $(1.33 \%)$, and Thailand $(0.53 \%)$. Compared with neurology, there was a greater contribution by Asian authors in neuroradiology and neurosurgery $(\mathrm{OR}=2.90 ; 95 \% \mathrm{CI}, 2.17-3.87$ and $\mathrm{OR}=2.48 ; 95 \% \mathrm{CI}$, 1.83-3.36, respectively). Although Japan had a large rate of contributions overall, there was a decreasing trend for Japan in the past 21 years in all 3 fields (neurology: OR $=0.89$; 95\% CI, $0.84-$ 0.94; neuroradiology: $\mathrm{OR}=0.94 ; 95 \% \mathrm{CI}, 0.91-0.98$; and neurosurgery: $\mathrm{OR}=0.92 ; 95 \% \mathrm{CI}, 0.88-0.95)$. At the same time, the contribution of China has significantly increased in all 3 fields (neurology: OR $=1.31 ; 95 \% \mathrm{CI}, 1.11-1.53$; neuroradiology: $\mathrm{OR}=1.14 ; 95 \% \mathrm{CI}, 1.07-1.22$; and neurosurgery: $\mathrm{OR}=1.13$; 95\% CI, 1.02-1.25) across the years.

Overall, American-authored articles were cited, on average $($ mean $=81.9), 1.25$ times more frequently than non-Americanauthored articles $($ mean $=65.2)($ Fig 4$)$. When we compared the total number of citations per number of articles between articles originating in the United States and outside the United States, neurosurgery articles from US institutions had a higher impact than those from non-US institutions in 11 of 21 years. In the neurology (14/21) and neuroradiology (16/21) fields, for most years, articles from American institutions had a higher impact than those from non-American institutions (On-line Table 2).

When we ran Poisson models, overall, there was a positive effect (coefficient $=0.22 ; 95 \%$ CI, $0.10-0.35$ ) between American institutions and the number of citations. This effect remained significant in the neurology (coefficient $=0.28$; 95\% CI, 0.110.45 ) and neurosurgery (coefficient $=0.21 ; 95 \%$ CI, $0.03-0.40$ ) fields, but there was no significant association between the number of citations and American institutions in neuroradiology (coefficient $=0.19 ; 95 \% \mathrm{Cl},-0.07-0.45)$. When we divided the study into two 10 -year periods to assess citation numbers, overall (all 3 fields combined) there was a positive effect between American institutions and the number of citations in both the first 10 -year (coefficient $=0.18 ; 95 \%$ CI, 0.17-0.35) and the second 10 -year block (coefficient $=0.20 ; 95 \%$ CI, 0.06-0.34) periods. This effect remained significant in neurology in only the first 10year period $($ coefficient $=0.29 ; 95 \% \mathrm{CI}, 0.07-0.51$ ) and in the second 10-year period for neurosurgery (coefficient $=0.21 ; 95 \%$ CI, 0.01-0.40), but there was no significant association between 


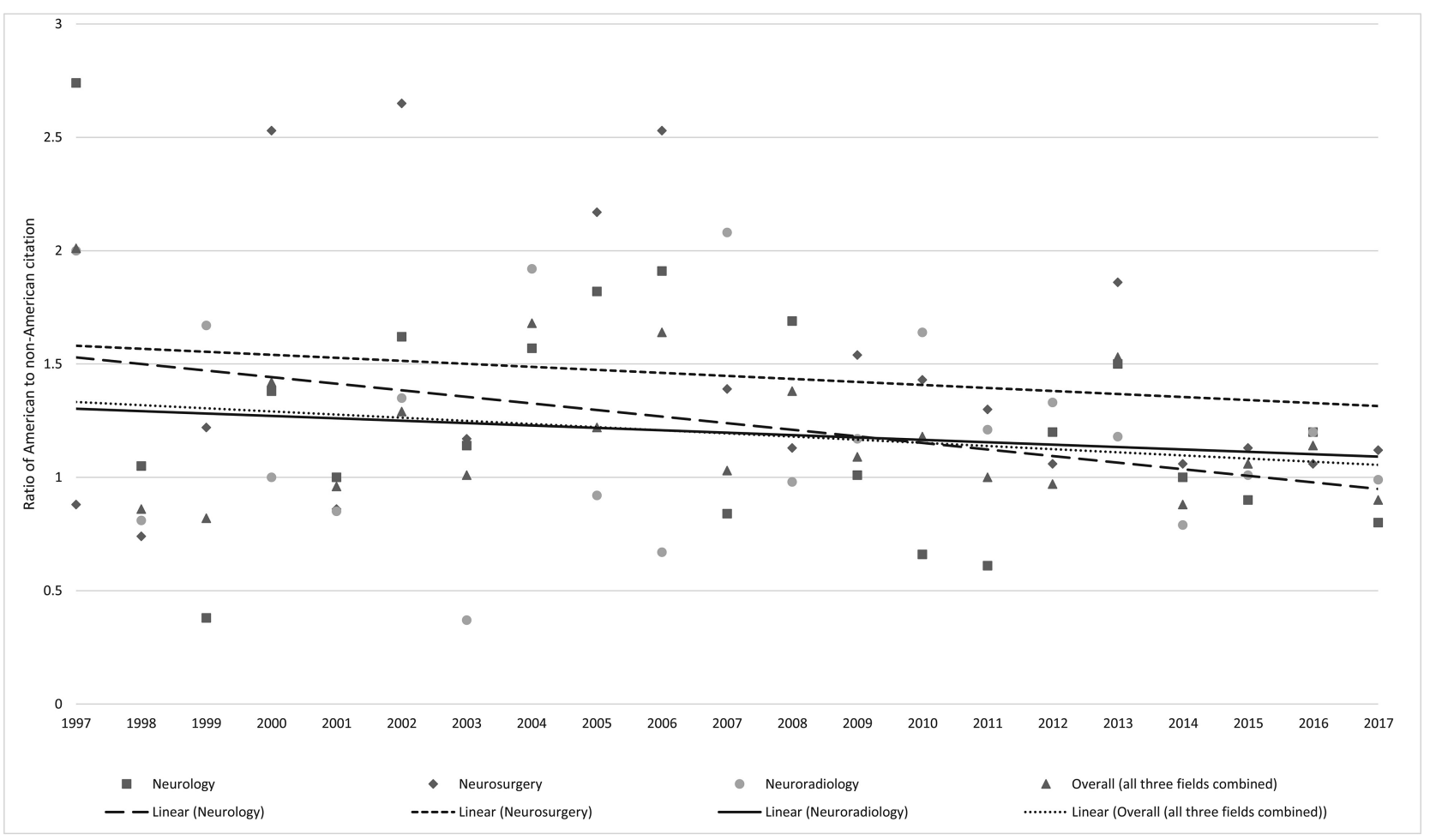

FIG 4. The citation trends of American versus non-American articles show a downward trend for all journals but remain in favor of American authors, except most recently in neurology, in which the trend crosses below the even mark.

the number of citations and American institutions in neuroradiology in either 10-year period.

\section{DISCUSSION}

We demonstrated the rates of American and non-American authorship in American-published clinical neuroscience journals across neuroradiology, neurology, and neurosurgery specialties during 21 years. As we hypothesized, we found a larger contribution of authors from non-American institutions in neuroradiology compared with neurology and neurosurgery. There was a significantly decreasing trend in American authorship ratios across the 21 years in neuroradiology, but we did not find any such significant trend in neurology and neurosurgery. In addition, Japan was the most frequent non-American country supplying publications in American neuroradiology and neurosurgery journals, while the UK was the leading non-American country in neurology. Nevertheless, the influence of Japan has been decreasing with time in all 3 fields, even as the contributions of China show a significant uptick in publications. Overall, we found that the contributions from Asian institutions have affected neuroradiology and neurosurgery more than neurology. We also found that American articles received more citations per article; this effect was more pronounced in neurology and neurosurgery and was not significant in neuroradiology.

We found that in 15 of 21 years, American neuroradiology journals published more articles with first authors from nonAmerican institutions than American institutions in the May edition. Although this effect can be seen in some years before 2007, it is more pronounced in the past 10 years in the neuroradiology field (Fig 1). Similarly, there was a tendency to publish articles with first authors from non-American institutions in neurology journals (12/21 years), especially in the last 7 years (Fig 1$)$. On the other hand, American neurosurgery journals, for most years, published more articles from American institutions (14/21 years). When we compared the 3 fields, neurology and neurosurgery journals had a higher ratio of America-to-non-American authorship compared with neuroradiology. In addition, we found a decreasing trend in American authorship ratios across the 21 years in neuroradiology. This trend could be due to several factors, including more familiarity with the English language through the universality of the Internet with English the preferred language of communication in the science world. ${ }^{8}$ This facilitates writing articles and the submission process for international authors. The narrowing of what previously was a technology gap between the United States and other countries could be another facilitating factor. Growth in global collaboration would be another reason for the observed result; when we looked at the first author's institution, however, there were articles with authors collaborating from different countries, especially in more recent years. Across the years, changes in research funding in the budget of the National Institutes of Health and in the budgets of foreign countries may affect research participation and publishing trends. ${ }^{9}$ The decline in Medicare reimbursement recently has also led to more emphasis on relative value unit production, even in American academic medical centers, and that may impact academic activities. ${ }^{10} \mathrm{We}$ also question whether the American millennial generation is less inclined to spend hours outside the traditional work week performing research the way previous generations may have.

The increased contribution of foreign countries can be beneficial to American journals; for example, China has studies with 
larger sample sizes owing to its massive population. The US literature is benefiting from outstanding researchers who do not live in United States; some studies, because of the regulations placed on American researchers, simply cannot be conducted in the United States. On the other hand, the decreasing trend may be a concern for US academic medical centers. We posit that both the clinical workload and lack of financial support for research could explain decreased American institution contributions in high-impact American journals. The clinical workload as measured by the relative value unit continues to increase ${ }^{11}$ in radiology, which may mean less time for research unless funded by grant support. Devoting more internal and extramural funds to the neurosciences and radiology has been recommended in the past. ${ }^{12}$ It is estimated, however, that National Institutes of Health support for diagnostic radiology will decrease in $2018 .{ }^{13}$ Inadequate funding would eventually lead to less education on clinical research for students, residents, fellows, and young faculty, setting the stage for a negative impact in the years ahead. ${ }^{10}$ Publishing in highimpact journals can be a bonus to attract younger, talented radiologists to academic settings as they decide between private and academic jobs. Increasing the funding resources and not relying on only government support are crucial to expanding the research activity. We also suggest that incorporating more training in research methodology in residency and fellowship programs may help overcome some hurdles that may prevent academic contributions by trainees. At a local level, more recognition by department chairs for manuscript publication/grant procurement rather than clinical activity could be accomplished by shifting monetary incentives, awards, public commendation, and advancement in rank in favor of academic output, not relative value unit production. Universities can educate the younger generation on the benefits of high-impact research and the occasional need for effort beyond the standard work week to accomplish those goals. Adding funded research years to residencies and offering these tracks as a separate Accreditation Council for Graduate Medical Education-approved program have been successful in such programs initiated at the University of Pennsylvania and Johns Hopkins.

Few studies have addressed the authorship trends based on nationality in the neuroscience fields. Lim et al ${ }^{14}$ assessed the first author nationality of 2 radiology journals, Radiology and the American Journal of Roentgenology, for a 10-year period. They found that the Japanese are the leading authors after Americans in these 2 general radiology journals. Our study also had this finding in neuroradiology. Lim et al also showed that authors from other Asian countries including Korea increased significantly in this period. ${ }^{14}$ In our study, we showed that of Asian countries, China is on the rise while Japan had a decreasing contribution trend in American literature.

The national origin of the institution may impact the publication and citation rates if the authors are from nondeveloped and non-English-speaking countries because there are barriers to access to advanced technology and language proficiency. ${ }^{15-17} \mathrm{We}$ found that from non-American countries, European followed by Asian institutions had the most articles in the American neurology and neuroradiology literature. In American neurosurgery journals, articles from Asia had an equal or greater number of contributions compared with European institutions. Most interesting, we observed an increasing contribution trend from Australia in all 3 fields of neuroscience.

We found that from 1997 to 2017, articles originating in the United States had higher average numbers of citations than articles originating in other countries for most years in all 3 fields and significantly in neurosurgery and neurology. Our results are in line with those of previous studies showing that the most cited articles usually originated in the United States. ${ }^{18-20}$

As other studies indicated, several factors are associated with a higher number of citations for articles originating in the United States, including the following: 1) the large size of the scientific and especially radiology community in the United States, 2) massive financial resources in the United States, and 3) American authors' tendencies to cite articles that originate in the United States rather than abroad, ${ }^{18,21,22}$ which may represent unconscious or implicit bias. This bias is defined as attitudes that affect understanding, actions, and decisions in an unconscious manner, favoring American publications. Journal editors confront implicit bias in peer review; though a large proportion of submissions to American journals come from China and other countries in Asia, these countries remain underrepresented in terms of manuscripts accepted. $^{23}$

Several limitations are noteworthy. First, we collected data from only 2 journals in each of the 3 fields and only 1 month (May issue) in each year. The 2 journals were selected on the basis of the Internet references provided for American journals that had the highest Impact Factor. The bias is that these are journals published in America. This might limit our generalizability, though we believe we collected many articles compared with other similar bibliometric studies. Second, regarding the number of citations in an article, we recognize that there is a direct relationship between publication year and the number of citations accumulated. The number of citations expected by 2017 for an article published in 2015 is likely much less than one that has $10-15$ years to accumulate citations. Nonetheless, this factor holds true for all articles and all 3 journals and would not be biased between American and non-American authors.

\section{CONCLUSIONS}

We have found that the proportion of non-American contributions to the 2 American neuroradiology journals that have the highest Impact Factor is higher than that for American neurology and neurosurgery journals. That international influence is increasing with time. Articles from Japanese institutions predominate in neuroradiology and neurosurgery, but articles from the UK have a greater impact on neurology; however, the impact from Japan is decreasing even as the contributions from China have risen. Whether from European or Asian countries, articles authored from these nations receive fewer citations in the literature than American-authored articles across all 3 clinical neurosciences, less so however in neuroradiology.

\section{ACKNOWLEDGMENTS}

We recognize Marco Carone (University of Washington) for his advice on the statistical tests to use for these analyses. 
Disclosures: David M. Yousem—UNRELATED: Consultancy: medicolegal expert witness; Expert Testimony: medicolegal; Payment for Lectures Including Service on Speakers Bureaus: American College of Radiology Education Center*; Royalties: Elsevier for 5 books. *Money paid to the institution.

\section{REFERENCES}

1. Yeung AW, Goto TK, Leung WK. The changing landscape of neuroscience research, 2006-2015: a bibliometric study. Front Neurosci 2017;11:120 CrossRef Medline

2. Peccora C, Hsu R, Yazdi CA, et al. Publishing trends in two American journals in anesthesiology: results of an 80-year geographical survey. J Anesth Hist 2016;2:6-12 CrossRef Medline

3. Scimago Journal \& Country Rank. http://www.scimagojr.com/ journalrank.php?category $=2728$. Accessed September 15, 2017

4. NEUROSURGIC.com. http://neurosurgic.com/index.php?option= com_content\&view $=$ category\&layout $=$ blog\&id $=101 \&$ Itemid $=$ 465. Accessed September 15, 2017

5. Scimago Journal \& Country Rank. http://www.scimagojr.com/ journalrank.php?category $=2741$. Accessed September 15, 2017

6. Welch Medical Library. http://welch.jhmi.edu/welchone/. Accessed September 15, 2017

7. COUNTRIES-of the-WORLD.COM. 7 continents of the world. https://www.countries-ofthe-world.com/continents-of-the-world. html. Accessed February 4, 2018

8. Drubin DG, Kellogg DR. English as the universal language of science: opportunities and challenges. Mol Biol Cell 2012;23:1399 CrossRef Medline

9. Press WH. Presidential address: what's so special about science (and how much should we spend on it?). Science 2013;342:817-22 CrossRef Medline

10. Meador KJ. Decline of clinical research in academic medical centers. Neurology 2015;85:1171-76 CrossRef Medline

11. Lu Y, Zhao S, Chu PW, et al. An update survey of academic radiologists' clinical productivity. J Am Coll Radiol 2008;5:817-26 CrossRef Medline

12. Alderson PO, Bresolin LB, Becker GJ, et al. Enhancing research in aca- demic radiology departments: recommendations of the 2003 Consensus Conference. Radiology 2004;232:405-08 CrossRef Medline

13. National Institutes of Health. Research Portfolio Online Reporting Tools. Estimates of Funding for Various Research, Condition, and Disease Categories (RCDC). https://report.nih.gov/categorical_ spending.aspx. Accessed January 30, 2018

14. Lim KJ, Yoon DY, Yun EJ, et al. Characteristics and trends of radiology research: a survey of original articles published in AJR and Radiology between 2001 and 2010. Radiology 2012;264:796-802 CrossRef Medline

15. Paiva CE, Araujo RL, Paiva BS, et al. What are the personal and professional characteristics that distinguish the researchers who publish in high- and low-impact journals? A multi-national webbased survey. Ecancermedicalscience 2017;11:718 CrossRef Medline

16. Dubey D, Sawhney A, Atluru A, et al. Trends in authorship based on gender and nationality in published neuroscience literature. Neurol India 2016;64:97-100 CrossRef Medline

17. Shekhani HN, Shariff S, Bhulani N, et al. Bibliometric analysis of manuscript characteristics that influence citations: a comparison of six major radiology journals. AJR Am J Roentgenol 2017;209: 1191-96 CrossRef Medline

18. Yoon DY, Yun EJ, Ku YJ, et al. Citation classics in radiology journals: the 100 top-cited articles, 1945-2012. AJR Am J Roentgenol 2013;201:471-81 CrossRef Medline

19. Brinjikji W, Klunder A, Kallmes DF. The $\mathbf{1 0 0}$ most-cited articles in the imaging literature. Radiology 2013;269:272-76 CrossRef Medline

20. Pagni M, Khan NR, Cohen HL, et al. Highly cited works in radiology: the top 100 cited articles in radiologic journals. Acad Radiol 2014; 21:1056-66 CrossRef Medline

21. Campbell FM. National bias: a comparison of citation practices by health professionals. Bull Med Libr Assoc 1990;78:376-82 Medline

22. Hong SJ, Lim KJ, Hwang HJ, et al. The $\mathbf{1 0 0}$ top-cited articles in pulmonary imaging: a bibliometric analysis. J Thorac Imaging 2017;32: 198-202 CrossRef Medline

23. American Association for the Advancement of Science. Journals and Funders Confront Implicit Bias in Peer Review. https://www.aaas.org/ news/journals-and-funders-confront-implicit-bias-peer-review. Accessed December 22, 2017 